\title{
Long-Term Results of Pisiformectomy in a Cohort of 57 Patients
}

\author{
Svenna H. W. L. Verhiel, MD ${ }^{1,2}$ Julia Blackburn, MBChB, MD ${ }^{1}$ Marco J. P. F. Ritt, MD, PhD ${ }^{2}$
}

Neal C. Chen, MD ${ }^{1}$
1 Department of Orthopaedic Surgery, Hand and Upper Extremity Service, Massachusetts General Hospital, Harvard Medical School, Boston, Massachusetts
${ }^{2}$ Department of Plastic and Reconstructive Surgery, Amsterdam UMC, location VUmc, Amsterdam, The Netherlands

Address for correspondence Svenna Verhiel, MD, Orthopaedic Hand and Upper Extremity Service, Harvard Medical School, Massachusetts General Hospital, Yawkey Center, Suite 2100, 55 Fruit Street, Boston, MA 02114 (e-mail: svennaverhiel@gmail.com).

J Wrist Surg 2000;9:465-469.

\begin{abstract}
Keywords

- complications

- patient-reported outcomes

- pisiformectomy

- pisiform excision
\end{abstract}

The pisiform contributes indirectly to wrist and hand function through its multiple soft tissue attachments and articulation with the triquetrum. ${ }^{1-6}$ The etiologic factors that are believed to contribute to pisotriquetral (PT) joint dysfunction are trauma (acute or chronic), instability of (carpal tunnel release, hypermobile joint), ganglion, arthritis, and flexor carpi ulnaris (FCU) tendinopathy. ${ }^{3,7}$

Clinically, patients with PT arthritis often present with pain localized to the ulnar side of the wrist and aggravated by contraction of the FCU. Symptoms of ulnar nerve paraesthesia may be present. ${ }^{4,8,9}$ Usually, nonoperative treatment, consisting of splinting or injection, is successful. Excision of the pisiform is an infrequently used option when nonoperative treatment is ineffective. ${ }^{5,7,8,10-13}$

Pisiformectomy relieves pain variably among studies, ranging from $50^{8}$ to $97 \%$ success rates..$^{5,7,12,14-16}$ Some authors report a high rate of return to work. ${ }^{5,14}$ Similarly, return of range of motion and grip strength are variable. ${ }^{5,10-14,16}$ Most received

February 19, 2020

accepted

April 28, 2020

published online

June 17, 2020
Copyright (c) 2020 by Thieme Medical Publishers, Inc., 333 Seventh Avenue, New York, NY 10001, USA. Tel: +1(212) 760-0888.
DOI https://doi.org/ 10.1055/s-0040-1712980. ISSN 2163-3916. 
of these observational studies consist of small cohorts of up to 30 patients $5,7,8,11,13-16$ and generally use patient-reported outcome measures. This study reviews the patient-reported outcomes of patients treated with pisiformectomy by one of three surgeons, and furthermore focuses on the complications and the need for and time to revision procedure.

\section{Materials and Methods}

This study was performed with the approval of our Institutional Review Board. We performed a retrospective multicenter study with cross-sectional follow-up of patients undergoing a pisiform excision at one of three large urban area hospitals (two level I trauma centers and one associated community hospital) between January 2002 and December 2017. We identified patients from the Institution's Research Patient Data Registry (RPDR) using Current Procedural Terminology (CPT) code 25210 "Carpectomy; one bone." Of the 358 patients with this code, 73 had a pisiform excision. Thirteen patients were excluded because their pisiform excision was part of a larger procedure (e.g., four corner fusion or PT excision) and three patients were excluded because of incomplete recordkeeping. Our final cohort consisted of 57 patients.

For all identified patients, demographic characteristics (age, sex, dominant hand, arthritis, diabetes mellitus, smoking status, alcohol dependency, manual labor as occupation), disease characteristics (affected hand, prior ipsilateral wrist trauma or surgery, symptom duration, indication for surgery, neurologic symptoms, radiographic, intraoperative and pathology findings), and treatment characteristics (prior treatment, concomitant procedures performed) were extracted from the hospital's electronic medical charts.

\section{Patient Characteristics}

Thirty-nine female (68\%) and 18 male patients (32\%) with a median age of 52 years (interquartile range [IQR]: 39-59 years) underwent a pisiform excision (-Table 1). The direct indication for their surgery was PT arthrosis in 48, FCU enthesopathy in 5, PT inflammation in 2, pisiform nonunion in 1 , and pisiform subluxation in 1 . Fifteen patients had a history of arthritis (25\%), most often osteoarthritis $(n=9)$, followed by rheumatoid arthritis $(n=4)$. Twenty-two patients (39\%) had a prior surgery to the ipsilateral hand, of whom 8 patients had a carpal tunnel release and 2 had a Guyon's canal release. Nineteen patients (33\%) gave a history of a definite injury proceeding the symptoms; the other patients had an insidious onset of symptoms increasing over a variable period. All patient characteristics can be found in - Table 1.

Diagnosis was based on the combination of clinical- and radiographic findings. The primary presenting symptom was pain, varying from mild to severe. The pain was worse with direct pressure to the PT joint. Sixteen patients (28\%) had symptoms of ulnar nerve compression at the wrist with paresthesia, numbness, or weakness in the appropriate distribution. Standard posteroanterior and lateral radiographs were obtained for all patients, to rule out other causes. Additional imaging (other than radiographs) was obtained for $56 \%$ of the patients, most often magnetic resonance imaging (MRI). This imaging confirmed PT arthrosis in 22 patients, FCU tendinopathy in 2, and PT instability in 1 . Additional findings were triangular fibrocartilage complex (TFCC) tears in 7 patients, a ganglion in the PT joint in 3 and extensor carpi ulnaris tendinopathy in 2 . A nerve conduction study was performed in 9 patients (16\%), 1 showed mild ulnar neuropathy at Guyon's canal, 2 showed mild median neuropathy, and the others were negative for ulnar or median neuropathy. Prior to operation, patients were treated with nonoperative measures, which included local steroid injections $(n=32)$, splints $(n=22)$, and nonsteroidal antiinflammatory drugs $(n=3)$. Patients underwent pisiformectomy after a median duration of symptoms of 13 months (IQR: 10-24 months).

\section{Surgical Procedure}

Excision of the pisiform was performed through a volar approach. An incision was made over the pisiform and carried down through the skin and subcutaneous tissue. The FCU was identified and followed distally to the pisiform. The FCU fibers were split in the longitudinal direction and then the pisiform was removed, while identifying and protecting the ulnar neurovascular bundle. The FCU was approximated with a suture. Postoperative immobilization was variable, though most patients were placed in a palmar splint for 10 days until suture removal.

\section{Outcome Measurement}

Medical records of patients were manually reviewed and assessed for complications, rate of unplanned reoperations, and type of reoperations.

Patients were invited by letter to complete patient-rated outcome surveys and over the phone or by email. In addition, they were asked to answer some additional questions regarding potential neurologic symptoms, pain around the incision area, and current use of painkillers. ${ }^{17}$ Two patients (3.5\%) passed away during the follow-up period, three (5.3\%) refused to participate, and sixteen (28\%) patients could not be reached. The 36 patients willing to participate formed the study's sample size, which reflects a response rate of $63 \%$. The median time from pisiform excision to the follow-up was 10 years (IQR: 4.5-14 years).

Patients were asked how their neurologic symptoms changed after the procedure (in case of preoperative neurologic symptoms), how many months it took before the area around the incision was completely pain-free, and if they currently take any painkillers for pain related to the pisiform excision.

The patient-rated functional outcome was measured by the Quick Disability of Arm, Shoulder and Hand (QuickDASH) questionnaire. ${ }^{18}$ The QuickDASH consists of 11 questions about daily activities and symptoms, each scored on a scale of 1 (no disability) to 5 (severe disability). These scores are transformed to a scale of 0 to 100 , reflecting patients' perception of physical arm function and symptoms. A higher score indicates more arm-related disabilities experienced by the patient. ${ }^{18}$ Patients rated their average pain in rest and during forceful forearm 
Table 1 Patient characteristics and their associations with outcomes

\begin{tabular}{|c|c|c|c|c|c|c|c|}
\hline Patient characteristics & $\begin{array}{l}\text { All } \\
(n=57)\end{array}$ & $\begin{array}{l}\text { Complications } \\
\text { p-value }\end{array}$ & $\begin{array}{l}\text { Responders } \\
(n=37)\end{array}$ & $\begin{array}{l}\text { Quick- } \\
\text { DASH } \\
p \text { - value }\end{array}$ & $\begin{array}{l}\text { Pain } \\
\text { rest } \\
p \text {-value }\end{array}$ & $\begin{array}{l}\text { Pain } \\
\text { rotation } \\
p \text {-value }\end{array}$ & $\begin{array}{l}\text { Satisfaction } \\
p \text {-value }\end{array}$ \\
\hline \multicolumn{8}{|l|}{ Demographics } \\
\hline Age in years, median (IQR) & $52(39-59)$ & $0.90^{\mathrm{a}}$ & $53(47-58)$ & $0.30^{c}$ & 0.52 & 0.21 & 0.61 \\
\hline Sex & & $>0.99^{\mathrm{b}}$ & & $0.34^{\mathrm{a}}$ & $0.64^{\mathrm{a}}$ & $0.91^{\mathrm{a}}$ & $0.33^{\mathrm{a}}$ \\
\hline Male, $n(\%)$ & $18(32)$ & & $10(27)$ & & & & \\
\hline Female, $n(\%)$ & $39(68)$ & & $27(73)$ & & & & \\
\hline Arthritis, $n(\%)$ & $15(26)$ & $>0.99^{\mathrm{b}}$ & $12(32)$ & $0.26^{\mathrm{a}}$ & $0.30^{\mathrm{a}}$ & $0.43^{\mathrm{a}}$ & $0.85^{\mathrm{a}}$ \\
\hline Diabetes, $n(\%)$ & $3(5.3)$ & $>0.99^{\mathrm{b}}$ & $2(5.4)$ & $0.40^{\mathrm{a}}$ & $0.28^{\mathrm{a}}$ & $0.19^{\mathrm{a}}$ & $0.21^{\mathrm{a}}$ \\
\hline Tobacco abuse reported in chart, $n(\%)$ & $7(12)$ & $0.58^{\mathrm{b}}$ & $5(14)$ & $0.81^{\mathrm{a}}$ & $0.74^{\mathrm{a}}$ & $0.72^{\mathrm{a}}$ & $0.83^{\mathrm{a}}$ \\
\hline Alcohol abuse reported in chart, $n(\%)$ & $1(1.8)$ & $>0.99^{\mathrm{b}}$ & $0(0)$ & NA & NA & NA & NA \\
\hline Manual labor, $n(\%)$ & $23(40)$ & $>0.99^{\mathrm{b}}$ & $14(38)$ & $0.049^{\mathrm{a}}$ & $0.33^{\mathrm{a}}$ & $0.49^{\mathrm{a}}$ & $0.74^{\mathrm{a}}$ \\
\hline \multicolumn{8}{|l|}{ Condition-related } \\
\hline Dominant side affected, $n(\%)^{c}$ & $28(58)$ & $>0.99^{\mathrm{b}}$ & $17(53)$ & $0.32^{\mathrm{a}}$ & $0.98^{\mathrm{a}}$ & $0.61^{\mathrm{a}}$ & $0.41^{\mathrm{a}}$ \\
\hline Prior trauma ipsilateral hand/wrist, $n$ (\%) & $19(33)$ & $0.68^{\mathrm{b}}$ & $11(30)$ & $0.31^{\mathrm{a}}$ & $0.29^{a}$ & $0.30^{\mathrm{a}}$ & $0.57^{\mathrm{a}}$ \\
\hline $\begin{array}{l}\text { Symptom duration prior to surgery in } \\
\text { months, median (IQR) }\end{array}$ & $13(10-24)$ & $0.86^{\mathrm{a}}$ & $13(10-24)$ & $0.97^{\mathrm{d}}$ & $0.61^{d}$ & $0.59^{d}$ & $0.44^{d}$ \\
\hline Indication for surgery & & $0.40^{\mathrm{b}}$ & & $0.21^{\mathrm{e}}$ & $0.38^{e}$ & $0.49^{\mathrm{e}}$ & $0.25^{\mathrm{e}}$ \\
\hline PT arthrosis, $n(\%)$ & $48(84)$ & & $29(78)$ & & & & \\
\hline FCU enthesopathy, $n(\%)$ & $5(8.8)$ & & $5(14)$ & & & & \\
\hline PT inflammation, $n(\%)$ & $2(3.5)$ & & $2(5.4)$ & & & & \\
\hline Pisiform nonunion, $n$ (\%) & $1(1.8)$ & & $0(0)$ & & & & \\
\hline Pisiform subluxation, $n(\%)$ & $1(1.8)$ & & $1(2.7)$ & & & & \\
\hline Symptoms ulnar nerve compression, $n$ (\%) & $16(28)$ & $0.39^{\mathrm{b}}$ & $15(41)$ & $0.69^{a}$ & $0.14^{\mathrm{a}}$ & $0.29^{a}$ & $0.99^{a}$ \\
\hline Additional imaging, $n(\%)$ & $32(56)$ & $0.22^{\mathrm{b}}$ & $19(51)$ & $0.11^{\mathrm{a}}$ & $0.12^{\mathrm{a}}$ & $0.33^{\mathrm{a}}$ & $0.24^{\mathrm{a}}$ \\
\hline \multicolumn{8}{|l|}{ Treatment-related } \\
\hline Prior conservative treatment, $n(\%)$ & $35(61)$ & $0.095^{\mathrm{b}}$ & $19(51)$ & $0.23^{\mathrm{a}}$ & $0.17^{\mathrm{a}}$ & $0.064^{\mathrm{a}}$ & $0.87^{\mathrm{a}}$ \\
\hline Prior surgery ipsilateral hand/wrist, $n$ (\%) & $22(39)$ & $0.70^{\mathrm{b}}$ & $13(35)$ & $0.41^{\mathrm{a}}$ & $0.19^{\mathrm{a}}$ & $0.92^{\mathrm{a}}$ & $0.63^{\mathrm{a}}$ \\
\hline $\begin{array}{l}\text { Concomitant procedure (other than } \\
\text { Guyon's canal release), } n(\%)\end{array}$ & $24(42)$ & $0.034^{\mathrm{b}}$ & $19(51)$ & $0.74^{\mathrm{a}}$ & $0.73^{\mathrm{a}}$ & $0.76^{\mathrm{a}}$ & $0.91^{\mathrm{a}}$ \\
\hline Concomitant Guyon's canal release, $n$ (\%) & $10(18)$ & $0.59^{\mathrm{b}}$ & $9(24)$ & $0.66^{\mathrm{a}}$ & $0.78^{\mathrm{a}}$ & $0.86^{\mathrm{a}}$ & $0.54^{\mathrm{a}}$ \\
\hline
\end{tabular}

Abbreviations: FCU, flexor carpi ulnaris; IQR, interquartile range; NA, not applicable; PT, pisotriquetral; QuickDASH, Quick Disability of Arm, Shoulder and Hand.

${ }^{a}$ Mann-Whitney $U$ test.

bFisher's exact test.

${ }^{\mathrm{C}}$ The dominant side was not specified for 9 patients.

'Spearman's rank correlation coefficient.

${ }^{\mathrm{e}}$ Kruskal-Wallis test.

rotation during the last month and overall satisfaction with the outcome of the procedure. For pain-assessment, the scale ranged from " 0 " representing "no pain" to " 10 " representing "worst pain imaginable." For assessment of satisfaction, the scale ranged from " 0 " representing "not satisfied at all" to " 10 " representing "couldn't be more satisfied."

\section{Statistical Evaluation}

We described discrete data using frequencies and percentages, and our non-normally distributed continuous data through medians and interquartile ranges. Bivariate analyses were performed to identify factors associated with our outcomes. To identify factors associated with our outcomes, complications, and reoperations, the two-sided Fisher's exact test was used for dichotomous and categorical explanatory variables, and an unpaired Mann-Whitney $U$ test for continuous explanatory variables. To identify factors associated with our QuickDASH outcomes, pain in rest, pain during rotation, and satisfaction, an unpaired Mann-Whitney U test was used for dichotomous explanatory variables, a Kruskal-Wallis test for categorical explanatory variables, and Spearman's rank correlation coefficient for continuous explanatory variables.

\section{Results}

At operation, macroscopic osteoarthritis was noted in 39 patients. Reactive effusion was seen in 8 patients, a PT ganglion in 3, FCU tendinitis in 3, and an osteocartilaginous 
body in the PT joint in 2 others. An abnormally large pisiform was described in 4 patients, and compression in Guyon's canal was seen in 2 others. Thirty-four patients underwent a concomitant procedure. Of these, 10 patients underwent a Guyon's canal release (18\%), 4 underwent a carpal tunnel release (7\%), and 6 underwent TFCC surgery (11\%). Pathological examination was performed for 42 patients (74\%). Pathology reports came back as osteoarthritis in 34 patients (of whom 14 mild and 6 severe).

\section{Complications and Reoperations}

The complication rate was $13 \%(n=7)$. Ulnar nerve symptoms, with paresthesia and numbness, were noted in 3 patients. Two patients had a local skin infection that was successfully treated with local debridement in 1, and with systemic antibiotics (amoxicillin/clavulanic acid for 7 days) in the other. A suture granuloma was reported in 2 patients. $A$ concomitant procedure (other than Guyon's canal release) was the only statistically significant factor associated with a higher complication rate ( $p=0.034$; - Table 1$)$. No reoperations were performed after the pisiform excision.

\section{Patient-Rated Outcomes}

Out of the 16 patients who had preoperative symptoms of ulnar nerve compression at the wrist, 10 patients reported that their symptoms had completely resolved after the surgery, 5 patients reported improvement, and in 1 patient the symptoms remained equal. The area around the incision was free of pain within 2 months in $69 \%$ of the patients.

After a median of 10 years (IQR: 4.5-14 years), the median QuickDASH score was 4.5 (2.3-16). Patients reported low scores for pain, with a median of 0 (IQR: $0-2$ ) for both pain in rest and pain during forceful forearm rotation. Patients were generally very satisfied, with a median score of 10 (IQR: 8-10) for overall satisfaction after the procedure. Manual labor was associated with a higher QuickDASH score (more disability). No other characteristics were associated with QuickDASH, pain, and satisfaction (- Table 1).

\section{Discussion}

We report on 57 patients who underwent pisiformectomy, predominantly for arthritis of the PT joint. Thirty-four of our patients had concomitant surgery, mostly for decompression of the ulnar nerve in Guyon's canal. Our complication rate was $13 \%$ but no patients required reoperations. Of the 37 patients who agreed to participate in our outcome surveys, the median satisfaction score was 10/10 (IQR: 8-10) and 69\% were pain-free within 2 months postoperatively. They also had good patient-reported outcome scores, with visual ana$\log$ scale (VAS) of 0 for pain at rest or on forceful forearm rotation (IQR: $0-2$ ) and QuickDASH of 4.5 (IQR: 2.3-16).

Our findings should be interpreted within the limitations of the study. We successfully contacted $65 \%$ of our cohort for information about their current clinical condition. There may be a selection bias in that patients who agreed to participate in our study might have better outcomes than those that declined. Second, we did not measure range of motion, grip strength in follow-up because of the logistical difficulties in re-evaluating patients. Third, we did not have preoperative patient-reported outcome measures to allow calculation of improvement in pain and function scores. Finally, it is important to recognize that pisiformectomy is sparingly performed. Among three surgeons, there were on average 4 pisiformectomies performed each year over a 16 years span.

The advantage of this study is that we were able to obtain patient-reported outcomes from 37 patients. This compares favorably with other cohorts ranging from $9^{8,10}$ to 30 patients. ${ }^{5,7,11,13,14,16,19}$ Carroll and Coyle described outcomes of 76 pisiformectomies but did not report any patient-reported outcomes. $^{12}$

Our patients were broadly similar demographically to patients who underwent pisiformectomy in other studies, as $68 \%$ were female with an average age of 52 years. In other studies, the average age of participants was in their late $40 \mathrm{~s}^{5,10,12-14}$ and between $56^{12}$ and $88 \%$ female. ${ }^{7,8,10,16}$ In keeping with other studies, all our patients presented with pain. $8,10,11,14$ In our study, $28 \%$ of patients had symptoms of ulnar nerve compression, while in other studies rates ranged from $20^{13}$ to $91 \%{ }^{8,10-12}$ Additional imaging was obtained for $56 \%$ of our patients, while in other studies MRI was used in between $14^{7}$ and $73 \%{ }^{10}$ of patients.

The indications for surgery in our patients were predominantly arthritis (48/57 patients), and this is similar to other studies where arthritis was the indication for surgery between $71^{7}$ and $92 \%{ }^{11}$ of patients. In five patients (8.8\%), FCU enthesopathy was the indication for surgery, which is lower than the $14 \%$ reported by another study. ${ }^{7}$ Thirty-four patients underwent concomitant procedures including 10 Guyon's canal release, 4 carpal tunnel release, and 6 TFCC surgery. In other studies of pisiformectomy, concomitant ulnar nerve decompression rates are slightly higher at $20^{16}$ to $25 \%{ }^{8}$

Our complication rate was $13 \%$, including three with ulnar nerve symptoms, two infections requiring either debridement or antibiotic treatment, and two suture granulomas. Prior studies do not document complications. $^{7,8,11-13,16,19}$ However, in these studies some patients went on to have further surgery to the distal radioulnar joint, ${ }^{12}$ resection of the distal ulna, ${ }^{12}$ or Darrach procedure. $^{8}$ This speaks to the confounding nature of ulnar-sided wrist pain, and caution should be taken before proceeding to pisiform excision.

The median QuickDASH score for our patients at 10 years follow-up was 4.5 (2.3-16). In a study from France that included 11 patients, postoperative median QuickDASH score was 27.6 at almost 8 years follow up. ${ }^{19}$ In another study of 35 patients, median DASH score after pisiformectomy was $25.3(12-38) .^{13}$

Furthermore, our patients also reported low scores for pain at 10 years follow-up with median VAS of 0 (IQR: $0-2$ ) for both pain at rest and during forceful forearm rotation. In a study of 35 patients, VAS scores after pisiformectomy were comparable: $1.3(0-3){ }^{13}$ In another study of 11 patients, postoperative VAS scores were also similar at 1.1. ${ }^{19}$ The patients that agreed to participate in our study reported a very high satisfaction with the outcome of their pisiformectomy (10/10, IQR: 8-10). 
This is similar to the excellent satisfaction reported in another study of pisiformectomy from the United States. ${ }^{16}$

We feel that our data can serve as a reference for decisions prior to electing pisiformectomy in cases with refractory pain associated with arthrosis of the PT joint or enthesopathy of the FCU/pisiform interface. It is important to recognize that we advocate for nonoperative management as much as possible as evidenced by the relatively small number of surgical procedures over 16 years among three hospitals. Using strict indications, complication- and reoperation rates are low. Furthermore, patients report limited disability on patient-rated outcome measures, low pain scores, and high satisfaction at mid- to late follow-up.

\section{Ethical Approval}

Informed consent was obtained from all individual participants included in the study.

All procedures were in accordance with the ethical standards of the responsible committee on human experimentation (institutional and national) and with the Helsinki Declaration of 1975, as revised in 2008. The Institutional Review Board of our institution approved this study under protocol \#1999P008705.

\section{Funding}

None.

Conflict of Interest

None declared.

\section{References}

1 Pevny T, Rayan GM, Egle D. Ligamentous and tendinous support of the pisiform, anatomic and biomechanical study. J Hand Surg Am 1995;20(02):299-304

2 Yamaguchi S, Viegas SF, Patterson RM. Anatomic study of the pisotriquetral joint: ligament anatomy and cartilagenous change. J Hand Surg Am 1998;23(04):600-606

3 Rayan GM, Jameson BH, Chung KW. The pisotriquetral joint: anatomic, biomechanical, and radiographic analysis. J Hand Surg Am 2005;30(03):596-602
4 Moraux A, Lefebvre G, Pansini V, et al. Pisotriquetral joint disorders: an under-recognized cause of ulnar side wrist pain. Skeletal Radiol 2014;43(06):761-773

5 Lam KS, Woodbridge S, Burke FD. Wrist function after excision of the pisiform. J Hand Surg [Br] 2003;28(01):69-72

6 Moojen TM, Snel JG, Ritt MJ, Venema HW, den Heeten GJ, Bos KE. Pisiform kinematics in vivo. J Hand Surg Am 2001;26(05):901-907

7 Gómez CL, Renart IP, Pujals JI, Palou EC, Busquets RC. Dysfunction of the pisotriquetral joint: degenerative arthritis treated by excision of the pisiform. Orthopedics 2005;28(04):405-408

8 Johnston GH, Tonkin MA. Excision of pisiform in pisotriquetral arthritis. Clin Orthop Relat Res 1986;(210):137-142

9 Kofman KE, Schuurman AH, Mulder MC, et al. The pisotriquetral joint: osteoarthritis and enthesopathy. J Hand Microsurg 2014;6 (01):18-25

10 van Eijzeren J, Karthaus RP. The effect of pisiform excision on wrist function. J Hand Surg Am 2014;39(07):1258-1263

11 Belliappa PP, Burke FD. Excision of the pisiform in piso-triquetral osteoarthritis. J Hand Surg [Br] 1992;17(02):133-136

12 Carroll RE, Coyle MP Jr. Dysfunction of the pisotriquetral joint: treatment by excision of the pisiform. J Hand Surg Am 1985;10 (05):703-707

13 Lautenbach M, Eisenschenk A, Langner I, Arntz U, Millrose M. Comparison of clinical results after pisiformectomy in patients with rheumatic versus posttraumatic osteoarthritis. Orthopedics 2013;36(10):e1239-e1243

14 Palmieri TJ. Pisiform area pain treatment by pisiform excision. J Hand Surg Am 1982;7(05):477-480

15 Paley D, McMurtry RY, Cruickshank B. Pathologic conditions of the pisiform and pisotriquetral joint. J Hand Surg Am 1987;12 (01):110-119

16 Campion H, Goad A, Rayan G, Porembski M. Pisiform excision for pisotriquetral instability and arthritis. J Hand Surg Am 2014;39 (07):1251-1257.e1

17 Bot AG, Becker SJE, Mol MF, Ring D, Vranceanu AM. Validation of phone administration of short-form disability and psychology questionnaires. J Hand Surg Am 2013;38(07):1383-1387

18 Kennedy CA, Beaton DE, Smith P, et al. Measurement properties of the QuickDASH (disabilities of the arm, shoulder and hand) outcome measure and cross-cultural adaptations of the QuickDASH: a systematic review. Qual Life Res 2013;22(09): 2509-2547

19 De Almeida YK, Piessat C, Athlani L, Dap F, Dautel G. Pisiformectomy in advanced pisotriquetral joint arthritis: a retrospective study of 12 wrists with a mean follow-up of 7.5 years. Hand Surg Rehabil 2019;38(03):165-168 